\title{
O DESPOTISMO NA DEMOCRACIA MODERNA
}

\section{DESPOTISM IN MODERN DEMOCRACY}

\section{Paula Gabriela Mendes Lima ${ }^{1}$}

\section{RESUMO}

Este texto visa compreender o termo despotismo democrático cunhado por Alexis de Tocqueville, pois além de se tratar de um termo fundamental para a compreensão do pensamento tocquevilliano e é uma categoria política importante para apreendermos melhor a experiência política de nosso tempo. Aposta-se que a semântica do despotismo democrático pode ser apreendida numa perspectiva singular a partir da análise do filósofo sobre a doutrina do interesse, considerando que esse despotismo de "espécie" nova é o resultado da ausência da articulação entre o interesse privado e o bem comum.

Palavras-chaves: despotismo, democracia, Alexis de Tocqueville, política e interesse.

\begin{abstract}
This paper aims to understand the term despotism democratic defined by Alexis de Tocqueville, as well as it is a key term for understanding the "tocquevillian" thought, it is an important political category to better apprehend the political experience of our time. It is believed that the semantics of democratic despotism can be apprehended in a singular perspective based on the philosopher's analysis of the doctrine of interest, considering that this new "kind" of despotism is the result of the absence of articulation between private interest and social well-being.
\end{abstract}

Keywords: despotism, democracy, Alexis de Tocqueville, politics and interest.

\section{Introdução}

Para Alexis de Tocqueville, "grilhões e carrascos são instrumentos grosseiros, que a tirania empregava outrora; mas em nossos dias a civilização aperfeiçoou até o próprio despotismo, que parecia contudo nada mais ter a aprender”. Dessa passagem do Livro I de A Democracia na América, compreende-se que as democracias modernas estão sujeitas a uma forma de opressão que não se confunde com os despotismos e as tiranias violentas e arbitrárias conhecidas até o início do século XIX. A sociedade que emerge após esse período, denominada pelo filósofo como estado

\footnotetext{
${ }^{1}$ Doutora em Filosofia Política pela Universidade Federal de Minas Gerais - UFMG, com estágio de pesquisa na Bibliothèque François Mitterand, mestre em Direito pela UFMG. Consultora jurídica da Assembleia Legislativa do Estado de Minas Gerais, atuante em movimentos de acolhimento de mulheres. Lattes: http://lattes.cnpq.br/1339419272418851. ORCID:http://orcid.org/0000-0002-7468-7648 E-mail:lima.paulagabriel a@gmail.com
} 
social democrático, aprimorou seus mecanismos de opressão, suscitando um despotismo com novas formas e novos conteúdos.

O objetivo deste texto é, essencialmente, compreender esse novo despotismo da era democrática, pois além de se tratar de um termo fundamental para a compreensão do pensamento de Alexis de Tocqueville é uma categoria política importante para apreendermos melhor a experiência política de nosso tempo. Para se referir a essa categoria, Tocqueville cunhou o termo despotismo democrático que se pretende aqui definir a partir da análise dos Livros I e II de A Democracia da América. Neles, o filósofo apresenta teses importantes referentes aos riscos e às ambiguidades da democracia moderna e expressamente afirma que há uma tendência da sociedade moderna em tornar-se um estado social democrático e despótico. Mas se trata de uma "espécie" nova de despotismo.

Tocqueville, como ocorre com vários de seus conceitos políticos, não define de maneira expressa o despotismo democrático, mas é possível delimitá-lo numa interpretação sistemática de seus textos, considerando as suas hipóteses sobre as causas, as caraterísticas e as formas possíveis de ação do despotismo na democracia. Não se trata de um conceito monolítico e, por isso, deve ser melhor compreendido a partir de uma perspectiva de análise.

Este trabalho aposta, por exemplo, que a semântica do despotismo democrático também pode ser apreendida numa perspectiva singular a partir da análise do filósofo sobre a doutrina do interesse, considerando que esse despotismo de "espécie" nova é o resultado da ausência da articulação entre o interesse privado e o bem comum. O homem da sociedade moderna democrática vive uma busca constante pelo seu bem-estar material e pela satisfação das necessidades de sua vida privada. Ocupado com seus interesses privados, esse homem se isola e não dispõe de tempo nem energia para participar da vida política onde a construção do interesse comum e do bem comum pode ser realizada.

O despotismo democrático decorre, especialmente, do isolamento e da não participação na política que deixa vazio o lugar do poder de mando e organização da sociedade. Esse lugar vazio é facilmente ocupado por um déspota, cujo discurso de ação é a ordem que torna possível aos indivíduos desfrutarem de seus bens materiais com segurança. Esse amor à ordem parece abrir o caminho para o poder absoluto, um poder central, imenso e tutelar que se torna a melhor solução para a manutenção da organização social democrática. Por esta via, na democracia o cidadão ama e deposita sua confiança no poder central, ficando suscetível ao despotismo e à tirania.

A proposta, então, deste texto é investigar a semântica do termo despotismo democrático a partir de reflexões sobre as formas que elas podem ser apresentadas numa democracia, bem como compreender as hipóteses tocquevilliana sobre os riscos desse estado social elaborada a partir da doutrina do interesse. Para tanto, divide-se este artigo em quatro partes. A primeira que apresenta 
as causas do despotismo na democracia moderna, considerando as ambiguidades dessa sociedade. Na segunda parte, focar-se-á nas características e formas de ação do despotismo democrático, relacionando-o com a desarticulação entre interesse particular e interesse comum. Na terceira, será uma breve análise das características e formas de ação do despotismo na era democrática moderna. E, por fim, a quarta parte será apresentada uma hipótese de interesse que pode contribuir para esse contexto que é denominada por Tocqueville por interesse bem compreendido.

\section{$2 \mathrm{O}$ despotismo como um risco constante nas democracias modernas}

O despotismo democrático é uma das formas de opressão possível no estado social moderno, apresentado por Tocqueville como uma novidade do início do século XIX. Na democracia moderna, para o autor, o despotismo é, em efeito, a forma de governo para a qual tende as democracias modernas. Ou seja, há uma disposição do estado social democrático, que advém de seus princípios, suas ideias, seus sentimentos e seus hábitos, ao despotismo, que se torna um risco real e permanente para essa sociedade.

Primeiro, é preciso esclarecer que não há, no âmbito da filosofia política um consenso sobre os sentidos do termo modernidade. Mas, neste texto, o objetivo é acompanhar o pensamento tocquevilliano que adjetiva a democracia como um estado social moderno, sendo isso fundamental para a sua sistemática conceitual. Alexis de Tocqueville apresenta a democracia como um evento histórico sem precedente. A partir de um critério histórico-empírico, sugerido por Marcelo Jasmin (JASMIN, 2005), pode-se compreender que o termo democracia visa nomear sociedades que ultrapassam as estruturas sociais que decorriam do feudalismo. Ela, com isso, fundia-se à ideia de modernidade. Considerando esse critério, portanto, a era democrática, citada pelo filósofo ao longo das suas obras, é o período que compreendemos como modernidade. E ela se diferenciava da denominada era aristocrática, considerada a época histórica em que as sociedades mantinham as estruturas herdadas do feudalismo, especialmente a sua organização de forma hierarquizada e divida por castas.

Do ponto de vista do critério teórico, também cunhado por Marcelo Jasmin, a era democrática e a era aristocrática são modelos de ordem social que se contrapõe porque possuem fatos geradores antagônicos. A democracia se funda no pressuposto da igualdade e a aristocracia na desigualdade. Não cabem aqui maiores esclarecimentos sobre a concepção de aristocracia para o pensamento tocquevilliano, mas deve-se seguir focando no fato de que a democracia moderna se manifesta a partir do processo de igualização.

A democracia, para o pensamento tocquevilliano não é uma forma de governo ou um regime político, mas uma maneira geral e abstrata de designar um modo de viver junto, afirma Roberto 
Legros (LEGROS, 2008). Ela se revela pela relação que os homens estabelecem entre si e com o mundo. Na democracia, continua Legro, é a sociedade que se transforma e é a condição humana que se transforma. Há uma alteração da base social que se sustenta no estado democrático sobre uma concepção de igualdade a qual modifica a relação entre os homens e a relação do homem consigo.

O homem democrático está inserido numa ordem social cujo fato gerador é a igualdade que ele denomina como igualdade de condições. Para Oliver Meuwly (MEUWLY, 2002), a igualdade de condições tocquevilliana implica a igualdade diante da lei, igualdade de chances devido à possibilidade de mobilidade social e à igualdade de consideração e respeito de um homem para com outro. É uma forma de nivelamento social entre os homens em vários âmbitos.

$\mathrm{Na}$ introdução do Livro I de "A democracia na América", Tocqueville afirma que essa igualdade é "o fato gerador de que cada fato particular parecia decorrer" (TOCQUEVILLE, 1990). Ela é o alicerce das leis, das decisões governamentais, dos costumes, dos hábitos particulares etc. O filósofo observa a igualdade como o fato singular da democracia, como a causa principal das inclinações e ideias do estado social. Ele quer compreender como e em que proporção a igualdade modifica e, simultaneamente, propulsiona esse estado social.

Simone Goyard-Fabre (GOYARD-FABRE, 1990) contribui para a compreensão dos diversos aspectos da igualdade na democracia tocquevilliana ao categorizá-la. Ela afirma que a igualdade pode primeiro ser considerada, no seu aspecto negativo, como abolição dos traços de feudalidade, da tradição nobiliária e dos privilégios. Ou seja, como supressão de hierarquias e diferenças entre classes. Ou como, em um sentido positivo, a construção e a modificação da ordem social. E, nesse sentido, a igualdade é um fato que influencia ideias, sentimentos e costumes, alterando-os e construindo bases diferentes de relacionamento entre eles. E a origem dessas alterações está na própria sociedade.

Considerando o critério negativo e o positivo apresentado por Simone Goyard-Fabre em relação à conceituação da igualdade, cabe esclarecer as observações tocquevilliana sobre esse tema expostas no célebre capítulo um da segunda parte do Livro II de "A democracia na América" denominado "Por que os povos democráticos mostram um amor mais ardente e mais duradouro pela igualdade do que pela liberdade". Tocqueville introduz este capítulo dizendo que "a primeira e a mais viva das paixões que a igualdade das condições faz nascer, não preciso dizer, é o amor por essa igualdade mesma" (TOCQUEVILLE, 2004). E, na nota dos rascunhos que abre o capítulo, afirma que essa igualdade sugere ao homem o sentimento de que não deve haver homens acima ou abaixo dele. Pode-se depreender que a primeira paixão do homem democrático é pela ideia da igualdade que significa o nivelamento dos homens no âmbito social e político de maneira que não haja nenhuma relação hierarquizada entre eles. 
Esse é, como visto nesta seção, o pressuposto da diferenciação entre a concepção de sociedade aristocrática e sociedade democrática e é a premissa inicial para se pensar sobre as vantagens e as desvantagens da igualdade. O primeiro ponto para se pensar refere-se à afirmação tocquevilliana de que o homem democrático tem amor pela igualdade. Para Simone Goyard-Fabre, a paixão pela igualdade é um motor poderoso da democracia e se traduz de forma simples como "um homem é um homem, como todo outro homem" (GOYARD-FABRE, 1990). É um axioma da igualdade a indiferenciação e a comutatividade aritmética, diz ela, que estabelece que um indivíduo é um indivíduo igual a outro indivíduo. A partir desse axioma originam-se todos os seus pensamentos e ideias dos homens democráticos que se apegam à igualdade, considerando-a o maior bem da sociedade.

Destaca-se disso o fato de que os homens democráticos priorizam a igualdade à liberdade. "Suportarão a pobreza, a submissão, a barbárie, mas não suportarão a aristocracia", diz Tocqueville. Para esses homens a desigualdade é intolerável. Eles querem a igualdade e a liberdade, mas, se não for possível obter a liberdade, contentam-se com a igualdade na escravidão. Há um gosto pela liberdade, mas uma paixão ardente pela igualdade.

A igualdade proporciona, cotidianamente, a satisfação de pequenos prazeres. Afirma Tocqueville que basta viver para desfrutar de cada um dos incidentes da vida privada que decorrem do processo de igualização. Os homens, por serem semelhantes, podem adquirir riqueza, buscar conforto, acumular fortunas e beneficiar-se de direitos que são normatizados de maneira igual para todos. Percebem-se no presente as suas vantagens.

Os males da igualdade, especialmente decorrentes do individualismo e do isolamento social, não se manifestam de forma tão imediata. A extrema igualdade pode, por exemplo, estabelecer ao longo do tempo um estado de apatia em que os homens não se interessam pelo espaço público e pela administração dos negócios políticos. A consequência mais severa desse processo é o estabelecimento de um estado social que, apesar de democrático, é despótico.

A apatia, o isolamento e o individualismo que decorrem da extrema igualdade gera a ausência de vínculos comuns capazes de unir os homens. Cada homem pensando apenas em si não busca refletir sobre os direitos e as necessidades de seus semelhantes. E essa indiferença é, para Tocqueville, uma virtude política para o despotismo. Diz ele que "os vícios que o despotismo faz nascer são precisamente os que a igualdade favorece" (TOCQUEVILLE, 2004). Trata-se de duas coisas que se complementam.

No despotismo, o bom cidadão é aquele que se encerra em si. Vive separado e sem vínculos com outros homens. Ele vive ordinariamente as suas necessidades privadas, buscando fortuna e bem-estar material. A sociedade, para ele, resume-se à manutenção da ordem e da segurança de forma que seja possível conservar as suas riquezas e o seu conforto. 
Nos últimos capítulos da quarta parte do Livro II, Tocqueville constrói o argumento de que os cidadãos isolados precisam de um poder central, sob pena de desordem. Esse amor à ordem parece abrir o caminho para o poder absoluto, um poder central, imenso e tutelar que se torna a melhor solução para a manutenção da organização social democrática. Por esta via, na democracia o cidadão ama e deposita sua confiança no poder central, ficando suscetível ao despotismo e à tirania.

Para além desses sentimentos, princípios e hábitos da democracia moderna que decorrem do princípio da igualdade de condições, é preciso compreender que há também categorias centrais da era democrática que aumentam a tendência desse estado social ao despotismo. São elas, a unidade, a uniformização e a centralização. Tocqueville afirma nos rascunhos do Livro II de A Democracia na América que quer desenvolver na quarta parte da obra as ideais de que o espírito humano nos povos democráticos suscita os mecanismos da unidade e uniformidade e que as ideias democráticas favorecem o estabelecimento do governo central, colocando em risco a democracia diante à ameaça do despotismo democrático.

No Capítulo II da Quarta Parte do Livro II, o filósofo irá desenvolver a hipótese de que "a ideia teórica e filosófica do governo nos povos democráticos, é a uniformidade e a centralização" (TOCQUEVILLE, 2005). Sua aposta, apresentada a seguir, é que decorre das ideias sobre governo e os sentimentos dos povos democráticos a unidade e a concentração de poderes, instrumentos políticos e sociais que dispõem essa sociedade a riscos.

Para Tocqueville, é uma consequência do estado social democrático baseado na igualdade certa massificação dos homens em que todos se tornam indivíduos iguais que tendem a ter os mesmos interesses, os mesmos gostos e as mesmas necessidades. Cada homem é, nesse contexto, apenas um pequeno elemento inserido numa multidão uniforme. Há, de um lado, um cidadão pequeno e isolado e, de outro, há uma massa semelhante que forma a sociedade.

Ao contrário das aristocracias nas quais há os súditos, os soberanos e os poderes secundários formados pelo corpo da aristocracia, nas eras democráticas, há a sociedade formada por uma multidão de pequenos cidadãos de um lado e o poder público de outro. Não existem poderes intermediários entre essas duas esferas, mas apenas sociedade de massa versus poder.

Os homens democráticos aceitam a existência desse poder da sociedade. Trata-se de um poder social que é emanado diretamente do povo, mas que não se mistura a ele. Os americanos, afirma Tocqueville, concebem a existência desse poder social, mas não instituem nenhum limite para ele. Ele torna-se um poder central e onipotente.

É um poder único que regulamenta da mesma maneira todos os habitantes, a partir de uma legislação uniforme. A regra aplicável a um cidadão sujeita a todos e repugnam-se quaisquer privilégios. E nos novos povos europeus que marcham para a democracia há uma estima para que 
este poder aja sobre temas públicos e privados, podendo interferir até no âmbito familiar. Ou seja, é um poder forte, central e que possui grandes prerrogativas.

O homem democrático reconhece e se sujeita a um poder central e esse poder central ama e estimula a unidade e a igualdade, que é o alicerce da democracia. Trata-se de um círculo vicioso. $\mathrm{O}$ estado social democrático tende a fortalecer a existência de um poder central e o poder central busca estimular as características desse estado social que são responsáveis pela sua conservação. Há uma relação perigosa de dependência do homem democrático que deseja conservar o seu bem-estar e vê no poder central uma tutela para essa conservação. Essa dependência é impulsionada pelo próprio poder que age de forma a mantê-la.

O homem democrático que se constitui moralmente pelo gosto pela tranquilidade e pela manutenção da ordem, que reflete a sua paixão pela segurança do seu bem-estar material, leva a democracia a desejar e a manter a centralização do poder. A centralização é, para Tocqueville, o governo natural da democracia e é inevitável.

Ela, somada à onipotência e à força do poder público (ou do Estado), leva-o a dirigir a si e a todos os cidadãos. Sob o argumento do controle da ordem e da segurança da sociedade, ele tende a um aumento do tamanho e um excesso de atribuições. Numa nota dos seus rascunhos, Tocqueville afirma, em clara alusão ao pensamento de Rousseau, que o soberano, nas eras democráticas, quer dirigir o povo e ser responsável pela felicidade de seus súditos.

Esse poder, que Alexis de Tocqueville chama de poder social, centraliza a sua ação ao mesmo tempo em que aumenta suas prerrogativas. A tendência do estado social democrático nesse contexto é um despotismo de uma espécie nova, em que o homem democrático estaria preocupado apenas com a sua vida privada, o seu bem-estar material e a sua fortuna, e, de forma quase imperceptível, o poder social iria pouco a pouco tomando conta de todos os aspectos de sua vida. Como afirma Jean-Louis Lamberti, o despotismo democrático nasce dos sentimentos e das ideias dos homens democráticos que o déspota quer oprimir (LAMBERTI, 1983). A própria constituição política e moral do estado social democrático parece o inclinar para o regime despótico.

Mas, para finalizar este tópico, é importante trazer uma advertência importante de Helena Esser dos Reis, trata-se de tema que não se irá desenvolver neste trabalho, mas que merece destaque como considerações finais (ESSER DOS REIS, 2012). O despotismo democrático não é uma consequência necessária da democracia, mas uma possibilidade decorrente da menor habilidade da arte humana em conduzir o processo de igualização, ou seja, de participação na esfera pública. A degradação do homem democrático decorre do abandono do seu destino e do destino da sociedade. É a apatia cívica que o degrada e o leva ao despotismo e não o estado social democrático. 


\section{0 despotismo como desarticulação entre interesse e bem comum}

Neste trabalho, aposta-se que há uma importante variável em relação à ameaça do despotismo no estado social democrático que é pouco investigada pelos comentadores e intérpretes do pensamento tocquevilliano. Trata-se da desarticulação entre o interesse individual e o interesse comum nessas sociedades modernas. Essa variável é importante porque o interesse é uma categoria política fundamental na democracia moderna e não pode ser negligenciada das análises das reflexões de Alexis de Tocqueville.

Na democracia moderna, como visto, o homem busca o seu bem-estar material e a satisfação das necessidades de sua vida privada. Ocupado em adquirir a própria fortuna, não dispõe de tempo nem energia para participar da vida política. Entretanto, esse homem não vive sozinho, mas em uma sociedade na qual, afirma Alexis de Tocqueville, os interesses unem os homens.

Tocqueville apresenta em "A democracia na América - Livro I" um modelo de sociedade democrática na qual não há essa desarticulação do corpo social: o estado social democrático norteamericano. A partir desse modelo, diz Tocqueville: "o que serve de laço entre os elementos diversos? O que faz de tudo aquilo um povo? O interesse é o segredo" (TOCQUEVILLE, 1964). Ao observar os EUA, Tocqueville compreende que a composição dos homens para a formação de um corpo político se deve à formação de um vínculo político baseado no interesse. O interesse impulsiona o homem a participar da vida política e a agir no espaço público. Por manter ativo o espaço público, o interesse se torna uma categoria política fundamental para o funcionamento e a conservação de uma sociedade democrática.

Entretanto, o móvel principal da ação do homem da sociedade moderna não é o interesse comum, mas é o seu interesse particular, definido por Tocqueville como as suas necessidades e seus desejos mais imediatos. Para o filósofo, ele é o "único ponto imóvel do coração humano" (TOCQUEVILLE, 2005), ou seja, é o motivo universal e invariável da ação humana. O homem da era democrática busca permanentente o que lhe é útil para assegurar a satisfação do seu interesse particular.

Disso decorre a sua compreensão sua compreensão sobre a importância da esfera pública para a satisfação das suas necessidades privadas. Mas ele vê a sua participação nos negócios públicos como um requisito importante para seus interesses particulares e não como um mecanismo para construção de um interesse comum. Para Tocqueville, a passagem do interesse particular para a construção do bem comum só é um possível a partir de um contraponto que se dá a partir da noção de liberdade política. O autor constrói o argumento de que seria preciso impor ao homem a sua participação nos negócios públicos, afirmando que "quando os cidadãos são forçados a se ocupar 
dos negócios públicos, são necessariamente tirados do meio de seus interesses individuais e arrancados, de tempos em tempos, à visão de si mesmo" (TOCQUEVILLE, 2004). Para o filósofo, os homens, na modernidade, posicionam-se um ao lado do outro sem manter nenhum vínculo. Não obstante, quando eles começam a tratar de negócios comuns, percebem a importância e a necessidade de agir junto com os seus semelhantes.

Mas esse contraponto não é uma disposição natural da democracia e só pode ser estabelecido com o tempo. O estado social democrático, ao contrário, é composto por homens cuja tendência ou atitude dirige-se à busca em viver exclusivamente para si e conforme sua razão. É natural do homem democrático o sentimento pelos interesses do momento presente, a busca pela satisfação de uma multidão de pequenos desejos, o interesse por pequenas ambições e o amor pela riqueza e pelo bemestar, como já visto. A novidade do pensamento tocquevilliano em "A democracia na América Livro II” está em nomear o sentimento natural por esses interesses como individualismo.

Tocqueville em A democracia na América - Livro II, diferencia o individualismo de egoísmo e, nessa oposição, é possível compreender a sua concepção de cada polo desses lados. Para ele, o egoísmo seria um sentimento irrefletido que leva o homem a se priorizar em relação a todas as outras coisas e pessoas. Trata-se de um "instinto cego", um "vício" que destrói todas as virtudes e que sempre existiu na humanidade. $\mathrm{O}$ individualismo corresponderia a um sentimento refletido que afasta o homem de seus semelhantes e o insere numa pequena sociedade privada composta por seus familiares e amigos íntimos. Apenas os mais próximos interessam ao cidadão. Ele não se preocupa com as outras famílias, nem com os que não estão presentes, como seus antepassados e os membros de gerações futuras.

Apesar de escolha racional, para Tocqueville o individualismo é também um vício que advém de uma avaliação errônea a respeito do papel do homem na sociedade: o cidadão julga que, a partir de suas luzes e de sua fortuna, ele pode se manter por si só em todos os ramos da sua vida. Ele não deve nada e nem precisa esperar nada de ninguém. Tal equívoco decorre do processo de igualização das sociedades modernas, caracterizada pela ausência de hierarquias sociais fixas comuns nas sociedades aristocráticas, que suscita o sentimento de que o destino do homem só cabe a ele mesmo.

O resultado do individualismo é um total esvaziamento das virtudes públicas, do agir comum, que pode, com o tempo, afirma Tocqueville, esgotar todas as outras virtudes e deslocar o sentimento refletido do homem para o egoísmo. Em decorrência disso, o filósofo afirma que nas notas de seus rascunhos que um dos grandes defeitos e riscos inerentes à democracia se refere especialmente ao sentimento do homem democrático em se concentrar naturalmente em si e nos seus interesses particulares. 
O isolamento do homem democrático gerado pelo individualismo e pela busca constante pela satisfação dos interesses privados é algo favorável para o desenvolvimento do despotismo. O despotismo, para Tocqueville, é "particularmente temível nas eras democráticas" (TOCQUEVILLE, 2004). Para o déspota é importante que os homens se encerrem em si, não criem vínculos com seus semelhantes e não queiram participar dos negócios do Estado. O cidadão tornase indiferente em relação à sociedade e isso é uma virtude pública para o déspota, pois permite que ele governe facilmente conforme apenas a seus próprios desejos.

Os homens democráticos, totalmente clausurados em si, não se vinculam socialmente. Diz Tocqueville, que eles se interessam só por si e chegam a não se comunicar e nem a se conhecer. Os homens nos países democráticos não conhecem seus vizinhos, seus colegas de trabalho, os trabalhadores que lhe prestam serviço ou mesmo os patrões que lhe comandam. Como envolver esses homens, preocupados apenas com os seus interesses particulares e com suas vidas privadas, na construção do interesse comum?

Aqui, novamente, encontra-se um lugar vazio. A desarticulação entre a satisfação dos interesses privados e a construção de um interesse comum retoma a necessidade de se entregar a um poder tutelar e central a estruturação de um bem comum. Nesse contexto, esse bem não será, efetivamente, "comum" no sentido de ser uma pluralidade de valores que resultam da relação entre o interesse particular de cada um com o interesse da sociedade. Não será algo construído a partir da organização das instituições e das práticas políticas realizadas entre os homens de determinado corpo político. Mas tende a ser uma harmonização dos interesses individuais pela sabedoria do déspota que, como se verá na seção seguinte, reflete na democracia moderna os interesses de uma tirania de "espécie" nova.

\section{0 despotismo democrático: definição e características}

A análise das condições de possibilidades do despotismo na democracia moderna, acima descrita, é um forte alicerce para a compreensão dessa nova forma de opressão. Dos argumentos expostos pode-se apreender quais são os seus novos conteúdos e formas, mas é importante nesta seção sistematizar e consolidar essa compreensão, deixando mais claro o que é o despotismo democrático.

Nas notas dos rascunhos do Capítulo VI da Quarta Parte do Livro II, Tocqueville questiona se o despotismo na democracia seria militar ou administrativo. Sem apresentar um argumento palpável, ele responde nos seus rascunhos que entre essas formas, provavelmente os estados sociais democráticos dirigir-se-iam para o espírito militar. Mas, para ele, trata-se de algo completamente novo e mais permanente. 
Alexis de Tocqueville afirma

\begin{abstract}
Nunca se viu, nos tempos passados, um soberano tão absoluto e tão poderoso que tenha empreendido administrar, por si mesmo e sem o socorro de poderes secundários, todas as partes de um grande império; não há nenhum soberano que tenha tentado submeter indistintamente todos os seus súditos aos detalhes de uma regra uniforme, nem que tenha descido ao lado de cada um deles para regê-lo e conduzi-lo (TOCQUEVILLE, 1990)
\end{abstract}

O filósofo, nessa passagem, apresenta o despotismo democrático como um governo de um soberano com grandes poderes administrativos, que lhe são centralizados, bem como poderes sobre os homens, considerados individualmente ou numa coletividade representada pela massa. Podemse condensar essas ideias na afirmação de que o despotismo democrático é, para o autor, uma forma de opressão, para a qual as democracias podem se dispor após o século XIX, que se particulariza por ser extensa, tutelar, paternal, absoluta, inteligente, durável e doce. Repetem-se, aqui, as adjetivações utilizadas pelo filósofo nos Livros I e II de A Democracia na América para delimitar os seus elementos e as qualidades distintivas.

Alexis de Tocqueville, dando um novo sentido à palavra despotismo, afirma que se trata de um poder extenso porque o soberano consegue penetrar cada dia mais no círculo de interesses privados do que qualquer soberano da antiguidade. Ele encontra na democracia um ambiente favorável para aumentar constantemente o seu tamanho e suas atribuições. Para o autor, nos EUA do século XIX, até o desenvolvimento industrial das democracias modernas irá contribuir para essa extensão, pois a classe industrial é extremamente regulamentada pelo governo que exerce crescentes atribuições sobre ela.

O despotismo democrático é doce, pois ele dirige a alma dos homens democráticos e não o corpo. Ele torna o espaço para a ação da vontade cada vez menor e realiza uma servidão doce, calma e regrada desses homens que não teria mais capacidade de agir a partir de sua própria razão. Para Tocqueville, trata-se de um despotismo doce que degradaria o homem sem os atormentar e sem o uso da violência, como será esclarecido na análise de suas formas de ação.

É tutelar e imenso por se tratar de um soberano que se ergue sob os homens individualistas da sociedade moderna para se encarregar sozinho das necessidades e sorte deles. Cuida, como já apresentado, da sociedade como um todo e da manutenção da ordem e da paz, tomando conta de cada detalhe da vida cotidiana e deixando os indivíduos livres para cuidarem apenas dos seus pequenos afazeres domésticos. Pode-se caracterizá-lo, por isso, também como um poder paternal já mencionado em autores como Rousseau, por dirigir suas ações em prol da felicidade dos súditos, um provedor de benefícios, necessidades e experiências.

No despotismo democrático, para Tocqueville, o soberano dirige suas ações para cada indivíduo e o molda a seu gosto, mas também abarca seu poder sobre toda a sociedade. Ele a 
transforma em um "rebanho de animais tímidos e industriosos, de que o governo é pastor" (TOCQUEVILLE, 2005). Estabelece-se, com isso, um tipo de servidão. Para Tocqueville, nesse contexto, é inútil encarregar esse cidadão de eleger o soberano, pois a eleição é um ato raro, curto e que não basta para tirar o cidadão da apatia e da servidão. Isso seria uma ilusão de emancipação momentânea, para Claude Lefort (LEFORT, 1991). Não parece que seja possível fazer uma escolha livre diante da servidão e da perda da faculdade do homem de pensar, sentir e agir a que leva o despotismo democrático.

Eleger por si um soberano não afasta a democracia de seus riscos, pois não basta combinar a representação nacional com soberania do povo para que haja manutenção e conservação do estado social. Trata-se de um momento rápido em que o homem democrático sai da dependência a esse poder tutelar, extenso e absoluto, mas retornam rapidamente a ela.

A onipotência do soberano também decorre da disposição da democracia à centralização. Já se viu que, ao contrário das aristocracias nas quais há poderes secundários formados pelo corpo da aristocracia, nas democracias, eles não existem. Há, em efeito, uma concentração de poderes nesse soberano que governa só, sem interferências e intermediações de outras instâncias.

Alexis de Tocqueville propõe alguns remédios aos riscos do despotismo na democracia, mas este texto visa apenas apreender o fenômeno em si. A definição sistematizada neste tópico apresenta-se como um fechamento do texto que caminhou do debate sobre as condições da democracia para o despotismo. Esse percurso reflete a afirmação de Jean-Louis Benoît de que o despotismo a qual tende quase naturalmente a democracia possui uma natureza endógena (BENOÎTE, 2017). A democracia levada ao extremo dela mesma e de suas condições de igualdade pode corroer o indivíduo e o corpo social. Uma harmonia desse estado social só é possível se combinarmos a igualdade a outras categorias políticas que devem ser conquistadas. A democracia é um estado social que traz na sua própria essência os elementos de seus riscos ao abandono do despotismo. E, por estar exposta a riscos constantes, deve ser permanente pensada em suas estruturas e formas. A democracia moderna é um estado social que pressupõe um movimento incessante de defesa, constituição e reconstituição em prol da manutenção do seu corpo político.

\section{0 interesse bem compreendido como um possível caminho}

Alexis de Tocqueville afirma nas notas de seus rascunhos que na primeira parte de " $A$ democracia na América - Livro II" conheceram-se os defeitos e riscos inerentes à democracia e que é importante observar na segunda parte da obra os possíveis meios de atenuá-los (TOCQUEVILLE, 1990). Em relação aos defeitos e riscos, ele se refere especialmente ao sentimento do homem democrático em se concentrar naturalmente em si e nos seus interesses 
particulares. E, um possível contraponto a esse sentimento, é a doutrina do interesse bem compreendido que sugere a união do interesse particular com o interesse comum de maneira que seja possível discernir cada um deles, mas que também seja possível que eles andem juntos. É essa doutrina que Tocqueville apresenta na segunda parte de "A democracia na América - Livro II" e que se pretende analisar nesta seção da tese.

Por interesse particular, em "A democracia na América - Livro II”, Tocqueville entende os desejos e as necessidades do momento. Nesse ponto, ele segue seus argumentos suscitados em " $A$ democracia na América - Livro I". É natural do homem democrático o sentimento pelos interesses do momento presente, a busca pela satisfação de uma multidão de pequenos desejos, o interesse por pequenas ambições e o amor pela riqueza e pelo bem-estar, como já visto. A novidade do pensamento tocquevilliano em "A democracia na América - Livro II" está em nomear o sentimento natural por esses interesses como individualismo. É uma tendência ou atitude do homem democrático viver exclusivamente para si e conforme a sua razão. Todas as ideias e sentimentos são dirigidas para si próprio.

Afirma Tocqueville, que "o individualismo é uma expressão recente que uma nova ideia faz nascer. Nossos pais só conhecem o egoísmo" (TOCQUEVILLE, 2004)i. Ele diferenciará no capítulo II da segunda parte de "A democracia na América - Livro II" o termo individualismo do egoísmo, que são, diz Jean-Lois Benoît, "falsos sinônimos" (BENOÎTE, 2017) e tal diferenciação já foi apontada neste texto. Com a separação dos termos, Tocqueville não realiza um julgamento moral sobre o termo individualismo que é um fato característico da democracia.

Trata-se de um comportamento é típico dos homens democráticos que são indiferentes uns com os outros e que não possuem vínculos familiares e sociais fixos (JASMIN, 2002). Os homens dos séculos aristocráticos, ao contrário, vivem ligados a seus concidadãos e aos membros da família. Há um respeito pelas gerações passadas que mantiveram ou construíram tradições e pelos descendentes que viverão conforme as tradições construídas.

O individualismo das eras democráticas é, também, um isolamento que repercute no distanciamento do cidadão em relação à sociedade. Ele reconhece a existência do semelhante, mas não se dedica ao outro e ao seu bem-estar. Nos povos aristocráticos, ao contrário, o cidadão chega a se esquecer de si, afirma Tocqueville, para poder cuidar e proteger os homens que estão numa posição acima ou abaixo da sua a fim de manter a estabilidade das posições sociais.

O individualismo é, ainda, um vício que, para Tocqueville advém de um juízo racional, mas errôneo. Trata-se de uma avaliação equivocada sobre a relação e o papel do homem na sociedade. Esse juízo errôneo é algo que decorre do processo de igualização das condições, pois ele suscita o sentimento de que o destino do homem só cabe a ele mesmo. O cidadão julga que, a partir de suas 
luzes e de sua fortuna, ele pode se manter por si só em todos os ramos da sua vida. Eles não devem nada e nem precisam esperar nada de ninguém.

Disso resulta, repita-se, um total esvaziamento das virtudes públicas, do agir comum, que pode, com o tempo, afirma Tocqueville, esgotar todas as outras virtudes e deslocar o sentimento refletido do homem para o egoísmo. Ou seja, o grande risco do individualismo democrático é esgotar-se em egoísmo ${ }^{\mathrm{ii}}$. Mas esse não é o único risco, ressalta-se que há outros que lhe são inerentes $\mathrm{sii}^{\mathrm{iii}}$.

O isolamento do homem democrático gerado pelo individualismo é algo favorável para o desenvolvimento do despotismo, como já visto neste texto. Tocqueville se coloca essa questão e busca uma possível solução para ela a partir da noção de liberdade política. Ele constrói o argumento de que é preciso impor ao homem a sua participação nos negócios.

Considerando o modelo norte-americano, o filósofo apresenta a possibilidade desse comprometimento forçado do homem para com a coisa pública a partir do estabelecimento de instituições livres. Um bom exemplo, são as instituições criadas no âmbito das comunas. Elas incentivam o homem a participar da vida política em que está inserido e ele consegue visualizar a importância desse agir comum para a satisfação das suas necessidades, interesses e desejos.

A liberdade e a constituição de instituições eletivas na democracia podem gerar disputas e, diz Tocqueville, ódios particulares, mas nunca gerarão uma indiferença geral que é o germe de um governo despótico (TOCQUEVILLE, 1990). Os americanos conseguiram, para o filósofo, combater o individualismo a partir da liberdade, ainda que as disputas políticas, as intrigas das eleições ainda fossem uma realidade.

Em “A democracia na América - Livro II”, Tocqueville refere-se não à construção do interesse comunal, mas a do interesse comum nos termos apresentados por Rousseau. É importante ressaltar que ao se utilizar do termo interesse geral em "A democracia na América - Livro II", Tocqueville apresenta, na verdade, interesse comum. É preciso ficar claro que neste ponto o enfoque é o interesse comum que resulta do acordo dos interesses particulares, seguindo o pensamento rousseuniano. São os interesses que se relacionam à construção da vontade geral.

A vontade geral é uma generalização das vontades particulares. Ela tem por objetivo fazer que se reconheça no interesse comum, afirma Bruno Bernardi, os interesses particulares. E a formação do interesse comum é indispensável para a existência da sociedade, pois, também para Rousseau, ele contribui para a associação dos homens que tendem a permanecer isolados. $\mathrm{O}$ interesse particular parece ser para Rousseau um conceito atribuído ao indivíduo e ao interesse comum à comunidade.

Para os americanos, não basta a representação dos interesses comuns dos cidadãos a partir de um sistema político representativo, mas é indispensável a participação direta do cidadão na vida 
política. A partir daí ele sentirá a importância de se relacionar com os seus concidadãos. Cita Tocqueville que:

\begin{abstract}
É difícil tirar o homem de si mesmo para interessá-lo pelo destino de todo o Estado, porque ele compreende mal a influência que o destino do Estado pode ter sobre sua sorte. Mas se é necessário fazer passar uma estrada nos limites de suas terras, ele perceberá à primeira vista que há uma relação entre esse pequeno negócio público e seus maiores negócios privados e descobrirá, sem que ninguém lhe mostre, o estreito vínculo que une, nesse ponto, o interesse particular ao interesse geral.
\end{abstract}

Esse exemplo citado por Tocqueville deixa claro que o homem precisa participar dos pequenos negócios da vida cotidiana da sociedade. Ele irá se interessar pelo bem público e enxergar a necessidade dos homens entre si em face das demandas comuns que surgem diariamente. Os negócios públicos mais gerais só ocupam alguns cidadãos, os pequenos ocupam todos.

A despeito dos sentimentos que separam os homens democráticos, é possível construir o gosto pelo interesse comum. O interesse particular é algo natural na democracia e o interesse comum é criado e construído a partir de um governo livre. Num primeiro momento, afirma Tocqueville, a participação do homem para a construção do interesse comum pode parecer uma obrigação imposta, mas com o tempo se tornará uma opção e ele adquirirá o gosto por ela (TOCQUEVILLE, 1990B). A participação se tornará para o homem democrático, nesse momento, não só um dever importante, mas também um direito político fundamental ${ }^{\mathrm{iv}}$.

Compreender o vínculo entre o interesse particular e o interesse comum é a base da doutrina do interesse bem compreendido. Essa doutrina é, para Tocqueville, uma doutrina filosófica (TOCQUEVILLE, 1990b) e uma justificativa moral e política para a ação do homem democrático na sociedade. $\mathrm{O}$ homem democrático norte-americano aplica cotidianamente essa doutrina e entrelaça esses dois interesses nos seus pensamentos, sentimentos e ações.

A razão e a experiência prática nos EUA indicam que algumas vezes e por seu interesse privado, o homem deve se ocupar dos outros. A doutrina filosófica do interesse bem compreendido refere-se à crença do homem de que para valer o seu interesse é preciso negligenciá-lo do detalhe. Exigem-se certos sacrifícios de interesses para fins de se alcançar um interesse maior.

Nos séculos aristocráticos, um pequeno número de homens poderosos imbuía na sociedade a concepção de dever moral dos homens. Exigia-se que se fizesse o bem de forma desinteressada à imagem e semelhança de Deus e era essa a doutrina moral prevalente (TOCQUEVILLE, 1990b). À medida que os homens vão se igualizando e se concentrando em si mesmos, torna-se necessário estabelecer outra doutrina moral, pois a ideia de sacrifícios realizados sem interesse não se justifica mais como o fundamento da ação. 
$\mathrm{Na}$ busca de uma nova doutrina, investigaram-se as vantagens de o cidadão agir concentrando-se no interesse. Alexis de Tocqueville, nas notas de seus rascunhos, afirma que há três diferentes doutrinas do interesse que dão fundamento moral e político para a ação humana. Essas diferenças são estabelecidas considerando as consequências políticas da utilização do interesse como uma teoria moral. Para ele, não se trata de doutrinas de grande valor moral, mas possuem operacionalidade na sociedade democrática. Tocqueville cita:

Distinções a fazer entre as diferentes doutrinas do interesse:

Há uma doutrina do interesse que consiste em crer que se deve dobrar o interesse dos outros homens frente ao seu e que é natural e razoável não ocupar-se senão com este. [...]

Há uma outra doutrina do interesse que consiste em crer que o melhor meio de ser feliz é pôr a serviço seu interesse e ser bom, honesto, ... em uma palavra, que o interesse bem compreendido exige que se sacrifique o interesse próprio ou ainda que para alcançar o seu interesse no geral deve-se com frequência negligenciá-lo no detalhe.

Eis uma doutrina filosófica que tem seu valor...

Há, enfim, uma doutrina infinitamente mais pura, mais elevada, mais imaterial, segundo a qual a base das ações é o dever. O homem penetra por sua inteligência no pensamento divino. Ele vê que o objetivo de Deus é a ordem e se associa livremente na medida em que está nele este grande desígnio. Ele coopera em sua humilde esfera segundo suas forças a fim de cumprir sua missão e obedecer seu mandamento. Ainda há aí interesse pessoal, pois há um prazer orgulhoso e íntimo em semelhantes pontos de vista, mas o interesse é aí tão pequeno, tão dissimulado e tão legítimo quanto possível (NOLLA, 2005).

A primeira doutrina citada é, na verdade, uma consequência de um egoísmo irrefletido e, para Tocqueville, nem deveria ser chamado de doutrina. A segunda é a doutrina filosófica do interesse bem compreendido analisada nesta seção. E a terceira refere-se a uma doutrina de participação e cooperação do homem para com outro de forma que o seu interesse particular, ainda que exista, fique quase desaparecido. Ela é muito utilizada pelo discurso religioso, especialmente do cristianismo, que afirma a necessidade de fazer o bem por amor a Deus e para alcançar a vida eterna.

O importante, neste trabalho, é a segunda doutrina que trata especificamente do interesse bem compreendido. Ignace Haaz afirma que no termo interesse bem compreendido considera-se interesse como interesse social, no sentido de não ser um interesse individual, que é "colorido" por certos princípios de justiça $(H A A Z, 2012)^{v}$. Não parece, entretanto, que Tocqueville se refira a um interesse social ou coletivo, e nem a um interesse particular. O interesse bem compreendido é algo que está entre esses dois extremos. É um cálculo realizado pelo homem democrático para agir conforme o autointeresse, mas considerando os diversos interesses e desejos que estão em jogo. De forma moderada, devem-se excluir pequenos desejos e visar ao interesse comum para se chegar à satisfação de outros interesses particulares maiores ${ }^{\mathrm{vi}}$. 
No trecho dos rascunhos citados, Tocqueville afirma que a doutrina do interesse bem compreendido é agir conforme seu interesse e ser bom e honesto. Vê-se que há uma preocupação não só com a satisfação dos interesses. Ela é útil para o homem na sua busca por seus interesses privados, mas ela também é uma doutrina que prega pela honestidade moral da ação. Ou seja, ela vai além do princípio da utilidade para incluir valores morais.

Tocqueville, ao descrever as doutrinas do interesse no seu rascunho, afirma de forma expressa que essas doutrinas não podem ser confundidas com a doutrina do útil (TOCQUEVILLE, 1990b). Parece haver no pensamento tocquevilliano uma clara distinção entre a doutrina da utilidade e a doutrina do interesse. $\mathrm{O}$ interesse bem compreendido não é uma teoria utilitarista, apesar de ter como uma das suas caraterísticas o princípio da utilidade ${ }^{\mathrm{vii}}$. $\mathrm{O}$ homem democrático age buscando o que é útil para a satisfação dos seus interesses particulares e concebe, nesse sentido, a possibilidade de combinar os interesses particulares com os interesses gerais, mas ele precisa considerar também como motivação da ação a sua honestidade ${ }^{\text {viii }}$.

Olivier Meuwly afirma que a proximidade de Tocqueville com o utilitarismo de Benthan é inegável, como defende Pierre Birnbaum e Jean-Claude Lamberti. No entanto, continua ele, Tocqueville adere à doutrina do interesse bem compreendido. A utilidade não é um princípio da sociedade e tem um valor secundário. A utilidade de que trata o pensamento tocquevilliano está ancorada no interesse, sendo apenas uma regra supletiva, de reforço para a doutrina do interesse bem compreendido.

O interesse bem compreendido estende a sua ação para além da doutrina utilitarista. Tratase de um reconhecimento da necessidade de, pelas luzes, realizar um cálculo que conduza o homem à busca do útil. O interesse particular continuará sendo o móvel da ação do homem democrático, mas cada um deverá compreender as nuances e os limites desses interesses para agir.

A doutrina do interesse bem compreendido refere-se à combinação do bem-estar próprio do homem com o de seu concidadão. Ela é a regra principal da ação humana no século democrático. Tocqueville, seguindo a tradição proposta por Montaigne, afirma que é o caminho reto que deve ser seguindo.

Para Olivier Meuwly, o homem democrático, a partir da doutrina do interesse bem compreendido, se convence de que a sua virtude se calca sobre o interesse. Ele conclui por si mesmo as vantagens individuais dos cidadãos trabalharem em prol do bem de todos(MEUWLY, 2002) ${ }^{\text {ix }}$. Introduz-se como um elemento constitutivo da ação do homem, a concepção de que o indivíduo deve contribuir para o bom funcionamento da coletividade. E, com isso, Tocqueville articula a ideia de interesse com a ideia de virtude.

A virtude nasce da autolimitação dos prazeres materiais tendo em vista o engajamento público, afirma Meuwly. Ou seja, há uma relação dialética entre a virtude e o interesse. A 
participação política do cidadão, impulsionado pelo interesse, depende das virtudes cívicas, e elas não se desenvolvem sem a criação de um regramento social direcionado para o exercício dos direitos políticos. A construção da virtude na democracia se realiza a partir da ação fundada no interesse bem compreendido que, como visto, direciona o homem ao caminho reto, que é o caminho da união entre interesse particular e participação na construção e manutenção do interesse comum.

Entretanto, ressalte-se, a doutrina do interesse bem compreendido não é suficiente para assegurar a virtude do cidadão na sociedade democrática. Ela favorece a compreensão da relação entre o interesse particular e o interesse comum, rompendo o isolamento dos indivíduos e auxiliando na construção do espírito público. Ou seja, ela pressupõe ao homem o agir virtuoso, mas é só um dos passos para a virtude pública.

A doutrina do interesse bem compreendido não é uma doutrina nova, mas ela se difunde e se aplica no estado social democrático americano como a base moral de todas as ações. A partir desse modelo, Tocqueville deduz que se trata da melhor doutrina moralista dos séculos democráticos. Para ele, "é uma doutrina pouco elevada, mas clara e segura" (TOCQUEVILLE, $2004)^{\mathrm{x}}$ e pode ser alcançada por todas as inteligências. Ela pode ser facilmente popularizada e aplicada em uma sociedade democrática.

$\mathrm{O}$ interesse bem compreendido não exige grandes devoções e ambiciosos sacrifícios. O homem não precisa ter virtudes extraordinárias para agir conforme esta doutrina, pois ela exige apenas pequenos sacrifícios cotidianos. Essa doutrina do interesse, sozinha, não é "capaz de fazer virtuoso um homem, mas forma uma multidão de cidadãos regrados, temperantes, moderados, previdentes, senhores de si; e, se não leva diretamente à virtude pela vontade, aproxima insensivelmente dela pelos hábitos" (TOCQUEVILLE, 2004). Ela não cria homens extraordinários, mas mantém um número maior de homens num nível ordinário aceitável.

Ainda que seja uma doutrina imperfeita, ela é, para Tocqueville, necessária (TOCQUEVILLE, 1990b), pois não há mais devoções cegas e virtudes instintivas que movem o homem a agir coletivamente para a construção e a manutenção do interesse comum. É uma forma de egoísmo esclarecido que possibilita a ação virtuosa do homem. E, nesse ponto, virtude e interesse estão de acordo.

O interesse bem compreendido auxilia o homem a vigiar as suas paixões do momento, convencendo-o a fazer pequenos sacrifícios e a satisfazer apenas pequenos desejos cotidianos. Ele afasta do homem o impulso para o interesse particular, contribuindo para a harmonia da ordem social composta por ações humanas mais regulares.

O homem democrático é um homem novo, que possui novas necessidades e novos interesses. $\mathrm{O}$ agir conforme o interesse bem compreendido é, certamente, uma caraterística singular desse novo homem que não pode se estabelecer numa sociedade aristocrática. Essa situação, as 
novas necessidades e os novos interesses exigem a consolidação de um novo estado social e um novo estado político.

Ou seja, há nos séculos democráticos um novo homem com uma constituição moral nova. E a consequência política disso está em se estabelecer uma nova sociedade cujo princípio de ação se difere das sociedades aristocráticas. A partir do processo de igualização social que era, para Tocqueville, uma marcha irresistível, surge um novo homem, como novos sentimentos e ideias e isso só pode gerar um novo estado social.

A igualdade funda o estado social democrático e contribui também para a constituição de moral de um novo homem. Um homem democrático é um homem de interesses, bem como a democracia tem como alicerce o interesse. São processos simultâneos, que se relacionam e se realizam de forma dependente.

Para Jean-Louis Benoît, nas sociedades democráticas os indivíduos são frágeis e carentes, pois são seres isolados e eles precisam se associar (BENOÎT, 2017). Uma das formas de associação se dá por um pacto que se constitui a partir do interesse bem compreendido. É importante lembrar que o pacto que une os povos democráticos é, em efeito, um contrato social no modelo apresentado por Rousseau ${ }^{x i}$. Além disso, diz Benoît, nos EUA o contrato social é aplicado considerando a doutrina do interesse bem compreendido.

Trata-se, continua Benoît, de uma escolha fictícia, pois é uma doutrina moral que influencia a ação cívica, moral e política do povo democrático (BENOÎT, 2014). Ela é um dos elementos essenciais da natureza da democracia, como é a igualdade de condições e a onipotência da opinião pública. Ela só se torna uma escolha real da sociedade quando é aplicada de forma concreta, como nos EUA, onde se estabelece um conjunto de interesses que garantem simultaneamente o interesse particular e o interesse comum.

A aplicação da doutrina do interesse bem compreendido depende do progresso das sociedades democráticas. Os povos democráticos e, principalmente, seus legisladores, devem fazer escolhas morais que direcionam o homem para agir conforme esses interesses. E essas escolhas serão bem realizadas se os cidadãos forem educados para isso.

A educação do homem democrático é fundamental para a aplicação do interesse bem compreendido que sustenta o pacto social dos povos democráticos. E, além de uma boa instrução, para Tocqueville, o homem deve completar sua educação a partir da prática política efetiva ${ }^{\text {xii }}$. Ou seja, o homem democrático é um homem de interesses e é capaz de manter um estado social democrático funcionando de forma regular se a ele for dada a possibilidade de aprendizado da liberdade política por meio da participação. 


\section{Breves considerações finais}

Alexis de Tocqueville era um pensador da democracia e contribuiu com reflexões sobre as ambiguidades e os paradoxos - termo que, nesta tese, deriva da lavra lefortiana - desse estado social. A partir de elementos internos da democracia, verifica-se o que é possível construir e conservar e, simultaneamente, observam-se os riscos e os problemas que surgem da democracia e que contribuem para a sua destruição. Tocqueville não é um opositor da democracia, mas um pensador crítico.

O elemento central e natural da democracia é a igualdade de condições: nela os homens são iguais, e isso significa que podem ter o mesmo status social, a mesma fortuna e o mesmo conforto material. Não há mais uma estrutura hierarquizada rígida, como na aristocracia, mas prevalece a possibilidade de mobilidade social. E "possibilidade" é o melhor termo a ser utilizado nesse contexto, pois não há uma efetiva igualdade, mas a possibilidade de um homem ser igual a seu semelhante. Na democracia, há ricos, pobres, patrões e empregados, como na aristocracia, mas a relação entre eles é diferente diante da permanente possibilidade de se tornarem semelhantes.

O alicerce da democracia é a igualdade como algo que está no espírito individual e que se manifesta de diversas formas no estado social. Por exemplo, entender-se como igual significa não aceitar uma superioridade intelectual, a priori. O homem democrático pensa e age conforme a sua razão, considerando-se independente dos seus semelhantes. E essa independência produz o fenômeno político do isolamento social. Os indivíduos tendem a se isolar e a viverem preocupados apenas com a sua vida privada e com o acúmulo de bens materiais.

A igualdade de condições na democracia resulta no individualismo como base da vida cotidiana e da ação do homem. Vive-se exclusivamente para si e conforme a sua razão. Ou seja, a igualdade, que é base da democracia moderna, tende a produzir homens isolados em suas mônadas, que não possuem nem tempo nem disponibilidade de espírito para tratar de assuntos que não concernem a sua vida doméstica.

Alexis de Tocqueville apresentou essas ambiguidades da igualdade de condições e refletiu sobre suas possíveis consequências. Para ele, a democracia fundada na igualdade pode sustentar regimes despóticos ou regimes de liberdade. O despotismo democrático, termo cunhado pelo filósofo, decorre do isolamento e da não participação na política. Os homens democráticos se isolam nas suas vidas privadas e deixam vazio o lugar do poder de mando e organização da sociedade. Esse lugar vazio é facilmente ocupado por um déspota, cujo discurso de ação é a ordem e a segurança que tornam possível aos indivíduos desfrutarem de seus bens materiais com segurança. Os homens 
democráticos, afirma Tocqueville, preferem a igualdade na servidão. E essa preferência é uma importante abertura para a instituição e conservação da servidão e do despotismo na democracia.

A democracia também pode resultar num regime de liberdade. A liberdade não é, para Tocqueville, algo natural desse estado social, mas deve ser produzida e conquistada pelos homens. Para o autor, é essencial exigir a participação dos indivíduos na esfera pública até que ela se torne algo natural da sociedade. Produzida, a liberdade política torna-se elemento indispensável para a harmonia da democracia, mas deve ser permanentemente objeto de luta.

O despotismo democrático apresenta-se como uma experiência próxima da que vivemos hoje no Brasil. Entretanto, nos ensina Tocqueville, ela não é a única possibilidade de direção de uma democracia em construção. Cabe a todos a compreensão e a participação da construção do bem comum para que a democracia seja, não uma servidão, mas uma harmonia entre liberdade e igualdade.

\section{Referências bibliográficas}

BENOÎT, Jean-Louis. Dictionnaire Tocqueville. Paris: Nuvis, 2017.

COUTANT, Arnaud. Une critique republicaine de la démocratie libérale. Paris: Mare \& Martin, 2007.

FROHNEN, Bruce. Virtue and the promise of conservatism: the lagacy of Burke \& Tocqueville. [EUA]: University Press of Kansas, 1993.

GOYARD-FABRE, Simone. La pensée politique d'Alexis de Tocqueville. Cahiers de philosophie politique et juridique de l'université de Caen, n. 19, p. 21-44, maio 1991

JASMIN, Marcelo Gantus. Alexis de Tocqueville: a historiografia como ciência da política. Belo Horizonte: Editora UFMG, 2005.

JAUME, Lucien. Tocqueville, les sources aristocratiques de la liberté. Biographie intellectuelle. Paris: Librairie Arthème Fayard, 2008.

HAAZ, Ignace. La solidarié, Chez Hegel, Von Hartmann, Tocqueville e Mill. Paris: L'Harmattan, 2012.

KINKIELKRAUT, Alain. Tocqueville et les emballements de la démocratie. Cahiers de philosophie politique et juridique de l'université de Caen, n. 44, p. 13-26, 2008.

LAMBERTI, Jean-Claude. La notion d'individualisme chez Tocqueville. [Paris]: Press Universitaires de France, 1970.

LAMBERTI, Jean-Claude. Tocqueville et les deux démocraties. Paris: PUF, 1983. 
LEFORT, Claude. Pensando o político: ensaios sobre democracia, revolução e liberdade. Rio de Janeiro: Paz e Terra, 1991.

LEGROS, Robert. La démocratie en questions. Cahiers de philosophie politique et juridique de l'université de Caen, n. 44, p.7-10, $2008 \mathrm{a}$.

MANENT, Pierre. Tocqueville et la Nature de la Démocratie, Paris: Julliard, 1982.

MEUWLY, Olivier. Liberté et société: constant et Tocqueville face aux limites du libéralisme moderne. Genève; Paris: Librairie DROZ, 2002.

NOLLA, Eduardo. Alexis de Tocqueville - De la Democratie en Amérique: première édition histórico-critique revue et augmentée par Eduardo Nolla. Paris: Libraririe Philosophique J. Vrin, 1990b.

REIS, Helena Esser. A liberdade do cidadão: uma análise do pensamento ético-político de Alexis de Tocqueville. 2002. $N$ folhas? Tese (Doutorado em Filosofia) - Curso de Pós-Graduação em Filosofia, da Faculdade de Filosofia, Letras e Ciências Humanas, da Universidade de São Paulo, São Paulo, 2002.

TOCQUEVILLE, Alexis de. De la démocratie en Amérique. 14. ed. Paris: Michel Lévy Frères, 1864.

TOCQUEVILLE, Alexis de. De la démocratie en Amérique II: première édition histórico-critique revue et augmentée par Eduardo Nolla. Paris: Libraririe Philosophique J. Vrin, 1990.

TOCQUEVILLE, Alexis de. A democracia na América: livro II - sentimentos e opiniões. Tradução de Eduardo Brandão. São Paulo: Martins Fontes, 2004.

TOCQUEVILLE, Alexis de. A democracia na América: livro I - leis e costumes. Tradução de Eduardo Brandão. 2. ed. São Paulo: Martins Fontes, 2005.

\footnotetext{
${ }^{\mathrm{i} J a u m e}$ afirma que o tema do individualismo é moderno, mas suas ideias já estão em Montaigne e Maquiavel (JAUME, 2009).

ii Para Jean-Claude Lamberti, a distinção realizada por Tocqueville entre individualismo e egoísmo reflete uma distinção criada por Rousseau no Contrato Social. Para o filósofo, o egoísmo é um defeito na natureza do indivíduo e o individualismo refere-se a um vício do cidadão (LAMBERTI, 1970). Tocqueville, certamente, relaciona o tema do individualismo ao tema da cidadania.

iii Eduardo Nolla, na edição crítica de "A democracia na América - Livro II", faz importantes observações sobre o termo individualismo. Para ele, o termo pode ser encontrado na obra de Tocqueville com outras palavras que designam a mesma ideia, como egoísmo individual, espírito de exclusão, força individual, espírito de individualidade, espírito de independência e independência individual (NOLLA, 1990b). Esta tese não se preocupou em verificar se esses termos possuem realmente a referência e o significado referido por Nolla, mas certamente há uma grande relação entre os termos citados e a ideia de individualismo. Outra importante observação de Nolla, refere-se à relação que ele estabelece entre o pensamento toqueviliano e o rousseaniano. Para ele, o termo individualismo utilizado por Tocqueville faz eco na concepção de amorpróprio de Rousseau.

iv A participação dos pequenos negócios da vida cotidiana pode se dar a partir do direito político de participação direta do indivíduo nas comunas, que são associações políticas, ou pela participação voluntária nas associações civis. Não é objeto desta tese aprofundar no tema da associação civil em Tocqueville, mas é importante citar que se trata de um instrumento fundamental para a construção do sentimento e do gosto do cidadão democrático pelo interesse comum. Os homens isolados são fracos e precisam aprender a arte de
} 
unir, afirma Tocqueville. E para esse aprendizado é fundamental a temática da associação na vida civil e a da liberdade de imprensa. A ação recíproca dos homens pode ser criada por meio das associações civis. E, para persuadi-lo de que é necessário para o seu interesse particular juntar-se aos outros, é preciso se valer dos jornais. Os jornais são, nos EUA, os grandes responsáveis pela ação comum dos homens, pois eles anunciam e convencem os homens da necessidade prática da associação. Vê-se que a associação civil, a associação política e os jornais são importantes exemplos de instituições que levam o homem a saírem do seu isolamento social (ver sobre o tema do papel da associação e dos jornais na democracia especialmente os capítulos IV a VII da $2^{\mathrm{a}}$ parte de "A democracia na América - Livro II").

${ }^{\vee} \mathrm{O}$ próprio autor afirma que "l'intérêt bien entenu ne signifie rien d'autre qu'il peut pleinement justifiable de sacrifier um bénéfice rapide, mais de moindre valeur, à condition qu'existe um bien supérieur même éloigné, fût-ce um objectif contraire au plaiser. L'intérêt bien entenu ne comprend implitament aucune une axiologie relative" (HAAZ, 2012). Ora, o interesse bem compreendido parece referir-se a uma motivação interna e calculada do homem, não se tratando de um interesse coletivo. Outro ponto importante é que Haaz parece acrescer ao conceito de interesse a ideia de justiça. Concordamos que a justiça é um valor importante para a aplicabilidade da doutrina do interesse bem compreendido e, como apresenta Helena Esser em sua tese, é um valor que advém da harmonia entre a igualdade e a liberdade. Destaca-se que Lucien Jaume trará à luz, no tocante à temática do interesse bem compreendido, as concepções de justiça e honestidade que não foram trabalhadas nesta tese (JAUME, 2008).

vi Para Bruce Frohnen, essa moderação decorre da virtude da prudência dos homens democráticos americanos. Isso é possível nos EUA, diz ele, porque os americanos reconhecem a necessidade de julgamentos calmos e moderados. A moderação é uma característica do americano e ele é capaz de produzir virtude. Na Europa, continua Frohnen, os homens são muito agitados para considerar calmamente as questões que envolvem o debate (FROHNEN, 1993).

vii Ignace Haaz afirma que não há evidências de que o pensamento tocquevilliano segue uma linha do utilitarismo. A utilidade a qual se refere Tocqueville tem uma finalidade simples: o prazer (HAAZ, 2012).

viii Anne Amiel diz que se trata de um materialismo honesto, que é o "amour du confort présent et de l'effacement de la 'spiritualité de l'âme"' (AMIEL, 2002).

ix Arnaud Coutant afirma que o interesse bem compreendido é para Tocqueville um instrumento moderno de luta com as derivações liberais das novas repúblicas. É uma virtude de espécie nova. Tocqueville parece, com isso, introduzir no seu discurso um elemento republicano moderno: a virtude. Para Coutant, há nesse ponto, um diálogo do pensamento tocquevilliano com Montesquieu que traz como princípio da república a virtude (COUTANT, 2007).

${ }^{x}$ Ignace Haaz afirma que o interesse bem compreendido pode ser encontrado nos Antigos, sendo um meio para se atingir um bem, que era a honestidade. $O$ interesse do homem visava ao seu pertencimento à comunidade e era fundamental agir conforme as leis úteis e a virtude da honestidade. O interesse bem entendido moderno, continua Haaz, ao contrário, corresponde ao princípio da igualdade em face às necessidades do indivíduo e não da comunidade (HAAZ, 2012). Marcelo Jasmin afirma que se trata de uma doutrina moralmente fraca, mas isso não é importante para Tocqueville que está mais preocupado com as suas consequências políticas do que moral (JASMIN, 2002).

xi Bruno Bernardi afirma que o Contrato Social de Rousseau é todo um tratado sobre o interesse (BERNARDI, 2006). Na passagem do estado civil para o contrato, o indivíduo não renuncia ao seu interesse. Mas ele "préferer à son intérêt apparent son intérêt bien entendu" (ROUSSEU, 1983).

xii Helena Esser dos Reis, no artigo denominado "Do hábito ao gosto: uma análise do processo políticopedagógico do Tocqueville" afirma que Tocqueville acredita profundamente na capacidade humana de se aperfeiçoar e de se transformar para produzir melhores condições de liberdade.

\section{Trabalho recebido em 02 de outubro de 2021 Aceito em 02 de novembro de 2021}

